\title{
Artists in the Classroom: \\ An Analysis of the Arts in Education Program \\ of the National Endowment for the Arts \\ Constance Bumgarner
}

Arts education is currently undergoing a dramatic paradigmatic shift in pedagogical theory and practice. The Romantic notion of the teacher as facilitator of unbridled and largely untutored creative self-expression is slowly ebbing as the concept of the arts teachers as educator and arts education as a sequentially taught, content-rich discipline gains ground. Expressive production and media-based technical proficiency are no longer the sole teaching objectives for many arts educators-a growing number of whom now agree that students must also have knowledge of and experience in historical, critical, and philosophical inquiry into the arts. With an understanding of the social and cultural environment in which an artist produces, it is reasoned, students may be better able to grasp the meaning of important works of art, and ultimately, discover a personal connection to that within a work of art which is significant to them and the society in which they live. In addition to this broadened concept of arts education in which the ideas and social context of art are deemed as worthy of study for the general student as are technique and the basic elements of an art form, many arts educators firmly believe that the arts must be taught in a sequential manner where students can build on what they have learned in a previous grade. This expanded vision of arts education is called "basic arts education" by the NEA and "discipline-based" or "comprehensive" arts education by others.

In response to wide-spread criticism that its Artists in Education Program remained too one-dimensional with its almost singular focus on the promotion and funding of artist residencies, the NEA announced a programmatic expansion in 1986. With great fanfare the Endowment declared that the mission of its new education program (retitled Arts in Education in 1988) was "to help make the arts basic to education." In 1987, the NEA introduced the Artists in Schools Basic Education Grants (AISBEG) category designed to encourage collaboration between state arts agencies, state departments of education, and local education agencies "in the development and implementation of long-term strategies ... to establish the arts as basic in education (NEA, 1989b, p. 16)". Arts in Education (AIE) application guidelines specifically noted the "development and implementation of sequential arts education curricula and program evaluation and documentation" as activities funded through AISBEG (ibid.). In 1989, the NEA released a five-year planning document (1991-95) in which the AIE Program's foremost long-term goal was heralded as being "to foster the adoption of comprehensive, substantive and sequential arts curricula in the Nation's schools" (NAEA, 1989, p. 12). In the 
same document, the Endowment cited the following "needs" as the top two priorities to be addressed in arts education:

1. The major need in arts education today is to ground the study and practice of the arts in the achievements of civilization, and in the role art plays and has played in the development of American culture and society...

2. More attention needs to be given to defining the content of arts education in terms of art forms ... [and] focus of instruction [including]: history, criticism, and aesthetics, as well as creativity, production, and performance (ibid.).

Artist residencies continued to receive the majortty of AIE funding, however. Of the $\$ 5.6$ million disseminated through the AIE Program in 1990 (just under $4 \%$ of the entire NEA budget), $\$ 3.6$ million or $65 \%$ was awarded to state arts agencies for the support of artist residencies under the State Arts in Education grants (SAEG) category (NEA, 1991, pp. 290-292). Approximately $\$ 1$ million was allocated to state arts agencies for the support of AISBEG initiatives while the remaining million was awarded to arts and education organizations through the Special Projects funding category for projects to "advance progress towards the arts becoming a basic part of education, K-12" (ibid., p. 296). In 1991, the NEA announced the discontinuation of Special Projects and the "merger" of SAEG and AISBEG into a single funding category titled Arts Education Partnership Grants (AEPG). "Artist residencies," the NEA assured its constituency would continue to "serve as a key element" in AIE Program initiatives.

The NEA's artist residency program is the largest and oldest federallysupported program for arts education in the nation. Poets-In-the-Schools, the prototype for the residency program, was established in 1966 (the Endowment's first year of operation) by the NEA as a pilot educational program and as a means to support artists. According to NEA Chairperson emeritus Livingston Biddle, the Poets-in-the Schools project was established not as a teaching project but to enrich learning, rather than build on it, step by cumulative step." The project's intent was to "permit the poet and pupil to communicate without a formal curriculum," and "produce excitement." "The same principles were applied to other art forms, "he explicated," ... state arts agencies followed in the tradition" (Biddle, 1988, p. 217). The artist residency program is based upon the assumptions that: (1) through exposure to artists students will learn about art; (2) artists have something special to offer students; and (3) the professed "professional" artist can teach art as well, if not better, than the career arts specialist-assumptions which have never been substantiated but yet are accepted as valid nonetheless; assumptions which remain the driving force behind NEA educational policy even now. This then is the genesis and character of the program that the NEA promulgates as "a common thread in the partnership fabric of the Endowment and the network

Working Papers in Art Education 1992 
of state arts agencies and as the basis [italics added] for increasingly comprehensive arts in education programs ..." (NEA, 1989b, p. viii).

Since the mid-1970s, Eilliot Eisner, Ralph Smith, Michael Day and other members of the arts education community have questioned the impact of the artist residency program on elementary and secondary arts education. For years, arts educators have asked: program?

- Who is the intended beneficiary of the artist residency

If $\mathrm{t}$ is the artist, is making artists into part-time teachers the best means to help them? ways?

If it is students, how many of them benefit by the program and in what

Do children living in poor and/or rural communities have the same opportunities to experience an artist residency as do children residing in affluent communities?

\section{- What do students learn from resident artists?}

Do they learn about the history, crtical theory, ideas, and social context of art as well as skills and techniques in production and performance?

In what ways does first-hand exposure to an artist affect students' attitudes and beliefs about art and artists? why?

What are artists able to teach students that arts teachers are not and

In light of the dramatic pedagogical shlits in arts education toward the development and implementation of more comprehensive arts curricula curricula which by the Endowment's own definition must be "sequentially instructed" and include "the history, crtical theory, and ideas of the arts as well as creation, production, and performance" - the NEA's continued support of the artist residency as the mainstay of its AIE Program deserves careful examination. It is also time to ask: To what extent is a broader, disciplinebased vision of arts education bolstered or undermined by the practices of resident artists and the educational policies of the NEA?

\section{Fesearch Methodology}

During the 1990-1991 school year, I visited over twenty artist residency programs sponsored by the NEA and Pennsylvania Council on the Arts in an attempt to begin to answer these questions. I observed painters, ceramicists, weavers, fabric designers, puppeteers, a mime and storyteller, 
poets, a playwright, as well as acting troupes, musicians, and a dance company teach and perform in elementary, middle, and high schools throughout Pennsylvania. Residency sites were located in communities as varied as the affluent Philadelphia suburb of Malvern, exceedingly rural, geographically isolated areas in the mountains of northcentral Pennsylvania, the Diocese of Pittsburgh, and an impoverished neighborhood in intercity Philadelphia. I interviewed resident artists, residency host teachers, school administrators, and of course, participating students. I inquired about the purposes, content, and expected outcomes of each residency, the kinds of arts education programs already in place, whether or not teachers had a planned curriculum, and what teachers and artists believed the primary objectives of arts education should be. In several instances, I was allowed to administer a student survey which included questions about what kinds of people students believed artists to be, what students thought they might learn from a visiting artist, and how artists get their creative ideas.

In order to better understand the structure, goals, and priorities of the Pennsylvania Council on the Arts' AIE Program in relation to the NEA's AIE Program and the AJE programs of other state arts agencies, text analyses of NEA and state arts agency-generated literature concerning overall agency goals, speclfic AIE program objectives, and grant application guidelines and selection criteria were completed. A series of telephone interviews with AIE program specialists from the NEA and seven state arts agencies was also conducted. These interviews focused on the role of the artist residency in agency educational initiatives and K-12 arts education, the significance of the NEA's recent merger of SAEG and AISBEG, and possible consequences of the merger (and subsequent policy and structural changes) on AIE programs at the state and local levels.

\section{Site Observations and Findings}

Residency program character and quality varies dramatically as a consequence of factors such as the nature of the residency setting, grade level, art form, residency structure and goals, who determined residency goals and learning objectives, how expliclitly or vaguely goals and objectives were defined, the professional expertise and teaching experience of the artist, the expertise of the host teacher, the knowledge-base and interest level of the participating students, and the number of students included in the residency and to what extent or in what capacity. However, among the wide range of actual residencies which I observed and the numerous other residency programs which were described to me by artists, teachers, and AIE program specialists, several importart commonalties directly related to residency outcomes and impact consistently emerged. As common sense might have predicted and as my research confirmed, residency character, quality, and ultimately impact primarily depended upon two factors: (1) the existence of a school arts program in the related residency area and (2) the quality of the existing school arts program.

Working Papers in Art Education 1992 
Schools without existing programs in the residency art form opted for performance assembly programs rather than actual residencies. Because there was no corresponding course of study, there was no teacher on-site with the expertise necessary to effectively build upon or incorporate the assembly material into the regular school curriculum. Because there was no pre-existing arts program, students generally had little knowledge of or experience with the art form to which they were being "exposed." Sometimes the students seemed to greatly enjoy the assembly programs, other times they visibly suffered through them. Although every school at which I observed a performance assembly had hosted other performing arts programs in previous years - 1 heard no plans at any of these schools (nor have I heard of any since) to develop and implement as much as a single drama or dance course much less a sequentially-instructed drama or dance program.

Regardless of the Endowment's and many state arts agency's protests to the contrany, it was obvious that the residency program was often used as a substitution for the development and implementation of bona fide school arts programs.

Schools with weak or minimal arts programs in the residency subject area frequently opted for short-term "mini-residencies" of two to five days in length. Such schools tended to minimize and "de-intensity" student exposure to resident artists by including a maximum number of students as residency participants and/or by spreading out the residency over several weeks. As a result, four, five, and six classes of over thirty students each would meet with the artist, as a group, for a total of perhaps no more than two to four hours. The artist would frequently give a schoolwide presentation/demonstration as well. In such circumstances there was obviously little time for any single students, regardless of their interest levels, to have obtained much individual attention from the artist. It is worthwhile noting that all of these students are included in the NEA's tally of students "reached" by the artist residency program annually (approximately seven percent of all K-12 students nationwide).

The basic elements of the art form and specific techniques served as primary residency content as artists taught students how to mix and match colors, how to achieve a certain effect with texture, relaxation exercises to help students "get in touch with their feelings," or how to construct a metaphor. Another common characteristic of residencies conducted in the context of a weak school arts program, was teacher non-involvement. In other words, the host teacher invariably stood back and watched. Residencies held at schools without existing arts programs or with underdeveloped arts programs were sometimes scheduled as after-school activities rather than during regular school hours, further lessening their linkage and proximity to the regular school curriculum.

Conversely, some remarkably impressive uses of the residency were witnessed at schools with strong arts programs. At Great Valley High School in Malvern, Mark Medoff (author of Children of a Lesser God) returned for

Working Papers in Art Education 1992 
the third year to work with a select group of young writers, drama students, and their English/drama teachers from across the state on the conception, development, and production of an opening scene. In the small town of Palmyra about a half-hour east of Harrisburg, the Windham Hill recording group, the Modern Mandolin Quartet, worked intensively with the junior and high school string players. Although relatively short in duration (six and five days respectively) the Medoff and Modem Mandolin Quartet residencies functioned exceedingly well in the provision of "master classes" involving a select group of students and their teachers. The work was advanced, intensive, specific, and highly collaborative. The host teachers were immersed in every aspect of the residencies; artist/teacher rapport was based on mutual professional respect.

Another excellent (and seemingly rare) use of the residency program was exampled by Nannette Clark's residency at Central York High School in York and Jane Todd Cooper's residency at the McCall School in Philadelphia. (Clark is a fiber artist and sculptress as well as the assistant director of the Afro-American Historical and Cultural Museum in Philadelphia. Currently a professional writer and poet, Cooper taught secondary English for thirteen years and has conducted a number of writing curriculum development workshops in Pennsylvania and New Jersey.) Both residencles were deliberately linked to the social studies curriculum and yet were intensively "hands-on." Students at each school explored past and current cultural exchanges between the African, European, and North American continents. The creation of their own works of art within a specific historical, cultural, and aesthetic framework served as a viable catalyst for the discussion, questioning, and analysis of the genesis and value of some of the students' own attitudes, beliefs, and practices.

The exceptionally high artistic calibre of the Medoff and the Modern Mandolin Quartet residencies and the ability of the playwright and musicians to contribute a unique and authentically professional perspective to the artistic pursuits of students and teachers were amply evidenced. Yet, had not the students and teachers been in the position to take advantage of these singular opportunities because of the strength of their own backgrounds in the selected art form, it is doubtful that either of these residencies would have ever been conceived in the first place. The full potential of Clark's excellence as a fiber artist and scholarship in the area of West African art and culture could have only been realized within the context of a comprehensivelyconceived arts program such as the visual arts program of Central York High School. Clark's integrative teaching methodology was in complete concordance with the daily teaching practices of York's visual arts specialist and residency host coordinator, Colleen Lehr. This artistically fertile and educationally holistic residency program did not result accidently but was generated because Lehr knew what type of residency she wanted for her students and deliberately selected an artist whose pedagogical philosophy matched her own. Similarly, Cooper's use of the Whole Language approach in the design and implementation of the McCall residency provided

Working Papers in Art Education 1992 
elementary classroom teachers a variety of accessible means by which to meaningfully assimilate residency activities into the regular curriculum. It is even probable that these four residencies will, to greater and lesser extents, favorably impact future curricular development at each of their host schools.

(The relatively advantaged position of the creative writing residency when compared to the markedly less generative environment within which residencies in the other arts disciplines [most conspicuously dance and drama] must operate is important to note. The NEA's selection of the Poets-in-the-Schools as their pilot educational program was, in retrospect, a wise decision. Perhaps what the pilot program's co-sponsors at the U.S. Office of Education and NEA knew then that was later forgotten in the rush to duplicate the residency formula in all arts subject areas was the profound importance and advantage of context. All elementary and secondary schools in America are required to provide their students with basic English courses and most schools offer courses in literature. A significant amount of creative writing - both prose and poetry - is olten included in the regular elementary writing curriculum and secondary English curriculum. As a result, all but the most educationally disadvantaged students have a relatively solid base upon which to pursue the study of poetry and creative writing. This is significant for creative writing residencies in that resident writers and poets are not usually expected to offer perennial instruction on the most fundamental levels and perhaps more importantly, there exists a curriculum in accordance with which the residency can be structured.)

What do students learn from artists? Basically, all of us learn what we have been prepared to learn.

Does a program which touches seven percent of the national elementary and secondary student population annually (three percent in Pennsylvania), for periods as short as forty-five minutes and rarely exceeding two or three weeks, increase the availability of the arts for the majority of Americans? Clearly the vast majority of Americans and school-age children do not come into contact with a professional artist in an educational setting. Yet for the small percentage of students who are able to participate in the residency program, the claim of increased availability may be justifiable. After all, "availability" is a vague, broad concept - and like all NEA overarching goals - can have almost infinite kinds and degrees of application.

Is increased arts availability more often than not served up via residency programs to that relatively affluent portion of the population which might readily afford their children access to arts education programs and nearby arts performances, exhibltions, and cultural institutions - If they so desired? Generally speaking, yes.

Has the artist residency program significantly helped to make the arts more basic to the $\mathrm{K}-12$ core curriculum in schools where the arts were not already deemed important? I saw no evidence to substantiate such claims.

Working Papers in Art Education 1992 


\section{AlE Program Advances and Retreats}

While it is normally risky to proffer any broad generalizations about the character and quality of an individual state arts agency AIE program solely on the basis of the study of its guidelines, goals, and grantmaking allocations, it appears entirely safe to propose that the support, propagation, and facilitation of artist residencies continues to be the primary activity of all seven state AIE programs included in my research. If the wording of agency guidelines and objectives sometimes obscures the primacy of the residency to AIE program operations, the numbers and percentages associated with budget allocation for the support of residencies and related services (relative to other AIE funding categories) clearly attest to the residency's dominion over all other program initiatives.

Although the facilitation and propagation of artist residencies remains the primary AIE focus, residency outcome expectations have increased considerably over the past three to four years. Many state arts agencies now encourage artists and teachers to collaboratively plan residency activities which are integrated or aligned with a planned curriculum. "Stand alone" residencies, including programs which consist solely or primarily of performance/demonstration assemblies and other such projects which are not directly linked to the regular school curriculum, are generally discouraged. This does not mean, however, that residency proposals which do not meet these suggested criteria are not funded. In fact, AlE personnel themselves report that the integrated residency is far more an ideal than a reality for most residency programs. That many schools lack any type of planned visual arts or music curriculum (whether comprehensive and sequential or otherwise) and curricula in dance and drama are largely non-existent in the vast majority of elementary and secondary schools across the country were seen as the primary reasons for this wide schism between what is preached and what is practiced.

Three of the seven state arts agency AIE spokespersons whom I interviewed vigorously denied the NEA's expansion of its AIE Program as having been the main impetus for similar kinds of program expansion by their agencies. Only one of the arts agencies included in this study supported any type of curriculum development-oriented intiative prior to 1987, however. ("Our Special Projects category may have been a sort of precursor [to AISBEG] as it was designed to accommodate non-residency projects of a basic education nature," explained the single staff member whose agency proved the exception.) Regardless of whether the primary catalyst for AIE program diversification and expansion originated at the state and local levels as a result of "a growing concern over educational reform" or at the NEA as a direct consequence of the 1986 shift in AIE funding policies, the fact remains that the vast majority of state arts agencies did not exhibit much interest in either the support of comprehensive curriculum development and implementation collaboratives with their state departments of education or the pursuit of long-range strategic planning to make the arts a more integral and 
relevant part of the core curriculum until the NEA began awarding grants for those endeavors specifically.

While the NEA professes "no hidden agenda" in its recent NEA AIE Program restructuring, the Endowment's capitulation to the demands of state arts agencies on a number of significant issues is foreboding nonetheless. By all accounts, the struggle between the state arts agencies and the NEA over AISBEG funding requirements was furious. (One AIE spokesperson candidly reported, "It was complete pandemonium when AISBEG was introduced at states assembly (the National Assembly of State Arts Agencies)." Three years ago NEA AIE staff and panelists appeared firm in their commitment to encourage and facilitate comprehensive arts curriculum development and implementation nationwide. State arts agencies were required to form partnerships with their respective state departments of education to be eligible for the receipt of AISBEG funding (less than $18 \%$ of the entire AIE Program budget in 1990). This requirement as well as the AISBEG focus upon education-oriented interests such as curriculum development and program evaluation were considered "restrictive" and even "oppressive" by a significant number of state AIE program coordinators. State AIE personnel complained that they were unable to administer such ventures largely in part because of their own lack of expertise. The NEA relented, effectively neutralizing these bet noires with the merger of AISBEG and SAEG monies into the single AEPG funding pool - the access of which required neither state department of education collaboration nor curriculum development initiatives from state arts agencies. Significantly, the NEA's "new" number one overall AIE Program goal - now listed prior to the goal of making the arts a basic part of the school curriculum -- is "to provide substantial arts education experiences for prekindergarten through 12th grade students." "These educational experiences," the Endowment emphasizes, "need not occur solely in or during the school day. For example, meaningful activities may take place in cultural organizations, during after-school programs or school vacation periods, etc." (NEA, 1991, p. 8).

For several years state arts agencies had petitioned the NEA for the institution of AIE block grants. At a 1989 AIE overview panel meeting, the establishment of block grants was "refuted" by staff and panelists as undeserved "entitlement" (Cleaver, 1989, p. 1). "Many panelists" went so far as to propose that although the state arts agencies "had clearly voiced their desire to be judged on the basis of progress towards goals identified for their own states ... the states have a right not to apply for funding if they don't agree with the Endowment's goals" (ibid.). The NEA now awards a "foundation grant" to all recipients of AEPG funding. The difference between a block grant and foundation grant is based upon the technicality of AEPG receipt. Only three out of fifty-six state and U.S. territory arts agencies were denied AIE funding in 1991. According to an NEA AIE spokesperson, state arts agencies "shouldn't have to defend their programs" and may currently be funded for "whatever works best for them" (Smith, 1992). That the facilitation 
and propagation of artist residencies is what works "best" for most state arts agency AIE coordinators and staff is no secret.

\section{Conclusions and Recommendations}

The artist residency program succeeds quite well at what it was originally designed to do. The presence of an artist in the classroom frequently produces "excitement" or "stimulation" to varying degrees among residency participants and can "enrich" the learning environment through the provision of alternative, informal, interactive "arts experiences" for students. That the residency program is immensely popular among NEA constituents i.e. state and local arts agency personnel and many of the artists and teachers who directly benefit from the facilitation of residencies - is also clear. After all, residencies provide numerous "professional" artists a more reliable income than does their own creative work and "makes good copy" in local newspapers - an asset not lost on arts advocates and politicians.

The residency program is currently asked to fulfill a vastly different function in a dramatically different educational context than that for which it was conceptualized, however. In 1986, the NEA promised that its "expanded" AIE Program had been re-designed to effect more significant, far-reaching impacts on elementary and secondary education than the provision of arts exposure and "enhancement" of existing school arts programs. The new AIE Program was to assist the arts education community in its struggle to develop and implement more broadly-conceived curricula, student assessment, and program evaluation methods in the arts. Yet what was proffered "as the basis" of NEA educational efforts to help make the arts basic to the K-12 curniculum? The "early 'residency' program" (NEA, 1989b) - of course!

The inherent nature of the residency program dooms such catholic pretensions to failure. For while the NEA's goal of making comprehensive, sequentially-instructed arts programs more central to the elementary and secondary curriculum, and thus more widely available to an increasing number of American children is clearly populist in intent, the philosophical underpinning and fundamental structure of the artist residency program is essentially exclusionary. The practice of placing artists in schools to teach and perform is exclusionary for three fairly obvious reasons;

- The effectiveness of the residency is greatly dependent upon the excellence and strength of its host institution whose own quality is generally contingent upon the socioeconomic status of its supporting community.

- Only a small minority of students "benefit" from the program annualiy, many of whom are "repeat customers" from middle to upper-income communities, towns, and suburbs. (Even it the NEA was in a position to double or triple its allocations for residencies - assuming there are enough "professional" artists willing and able to implement a larger program - it

Working Papers in Art Education 1992 
remains that only a fraction of American school children would have the opportunity to work with an artist for a sum total of no more than a few hours.)

- The assumption upon which the residency program is grounded -that the better one makes art, the better one is able to teach it - reinforces the traditionally narrow, one-dimensional vision of arts education within which the attainment of technical proficiency in an art form is seen as the most important objective of its study. While being able to competently and expressively draw the human figure, play a polonaise, deliver a Shakespearean soliloquy, perform a classical pas de deux, and compose a sonnet are admirable accomplishments, the fact remains that most of our nation's forty-six million elementary and secondary students will not pursue careers as professional artists and may therefore be better served by a broader, more general and integrative education in the arts.

Even more detrimental to the evolution and improvement of K-12 arts education than the residency program's failure to significantly advance the goal of making the arts basic is the insidiousness of the residency in actually subverting such goals. Perhaps in no other profession is Shaw's adage -- "He who can, does. He who cannot, teaches." - taken more seriously or verbalized with greater vehemence than in many artistic circles. This attitude-offshoots of which surfaced regularly throughout my conversations with resident artists - is obviously detrimental to the development of lasting partnerships between artists and arts teachers, arts and school administrators as well as the greater arts and arts education communities at large.

Additionally, the underfying thesis of the artist residency program -- i.e. "That [a] high level of artistic competency is a necessary condition for the effective teaching of art" (Eisner, 1978, p. 16), a competency level imported into the schools via professional and semi-professional artists -- coupled with the ardent insistence among resident artists and arts agency personnel that artists are not teachers but artists relays confusing, and at times, even negative messages about the perceived credibility of and need for the professional arts educator. To bill oneself as an "artist," it would seem, automatically confers a higher status than that of "teacher."

(A difference in rank between artist and teacher can certainly be inferred from the universal state arts agency half-day studio requirement which stipulates that fifty percent of the residency be apportioned to the artist's pursuit of his or her own creative endeavors. "The artist can reserve the right to structure [her or his studio time] to suit his own needs, which also includes hanging a 'Do not disturb' sign on the door," the South Carolina Arts Commission advises (SCAC, 1991, p. 8). In striking contrast, most arts teachers are not afforded so much as a daily planning period by their school boards. Paradoxically, not one of the artists with whom I spoke was particularty enthusiastic about the half-day they were expected to create in-residence. Several artists were in fact outright disgruntled calling the requirement "bogus" and "a waste of time." A genre watercolorist who painted the quaint houses and shops of the rural communities in which she generally

Working Papers in Art Education 1992 
worked proved the only exception to the otherwise unanimously held opinion that artists are not able to create "on display.")

As the voices of arts agency personnel collectively rise to indignantly deny the validity of such observations, I would not think it too impertinent to ask: When the NEA and its network of state arts agencies across the country select a program whose main function is to encourage the placement of artists in schools to demonstrate, perform, work on-site, in short to teach as their primary means of addressing the educational needs of students in the arts - what then is relayed to students, arts teachers, school administrators, and parents about the worth of their existing arts programs, the competency of their arts teachers, or the need to support the development of comprehensive, sequentially-designed arts curricula except that the professional arts community believes that artists can accomplish what arts teachers cannot? What conclusion might one draw about the efficacy of the residency program to improve the quality of arts education and advance its curricular status in the case of a school system which raised $\$ 32,000$ for the implementation of a regional residency program yet denied a requested allocation of $\$ 2,000$ to send visual arts teachers to a state curriculum development conference? What message does the encouragement of such practices (whether directly or indirectly) by the NEA and many state arts agencies send to the arts education community? The message - loud and clear - is that arts agencies and artists are not in partnership with schools and arts educators but in competition.

As recently as 1991 , the goal to "make the arts basic" was intrinsically interwoven with the widespread development and implementation of sequentially instructed, comprehensive school arts programs - a notion which was in turn closely linked to the AISBEG program. Although the phrase "to make the arts basic" has lately assumed the character of a mantra among arts agency personnel (all of whom seem sincere in their embracement of the concept - even if, as one AIE coordinator with whom I spoke admilted, "I'm not sure what [the phrase] means anymore"), its original connection to the embattled "AISBEG agenda" seems to have been deliberately obscured in the NEA's 1992 AEPG application guidelines. This is an unfortunate step backwards for the Endowment and ultimately for the entire arts education community. For after careful study and analysis of the artist residency program, it is my sincere belief that "the basis for increasingly comprehensive arts in education programs ${ }^{*}$ - and by extension, increasingly comprehensive and accessibie arts education programs - cannot be the artist residency but must be firmly rooted in the support and facilitation of broadly-conceived arts curriculum development and implementation efforts at the state, district, local, and perhaps even national levels.

The importance of federal funding in shaping state and local educational policy should not be underestimated. (The 1965 passage of the Elementary and Secondary Education Act [ESEA] provides a dramatic example of the impact of federal funding on arts education specifically. ESEA

Working Papers in Art Education 1992 
Title $V$ funds allocated for the improvement of state departments of education enabled many states to hire curriculum advisors in the arts for the first time. Title III supported the development of innovative programs which markedly advanced arts curriculum research and the development of a national network of arts education leadership. [McGeary, 1990].) It is time for the arts and arts education leadership of this country to fully and responsibly acknowledge the deleterious influence of the artist residency program on $\mathrm{K}-12$ arts education when championed as the fundamental means of a federally or state-supported campaign to make the arts basic to student learning. The obvious and longstanding discrepancies between NEA AIE goals, policy, and practice must be addressed and corrected. This is a tremendous challenge to be sure, but when at least one federally-supported arts education program is operative wherein there is no doubt of the identity of its primary benefactors - the majority of the nation's elementary and secondary students -- one well worth the trouble. With all due respect and with no illusions about the difficulty of the charge, I submit the following series of recommendations for the reconsideration and restructuring of NEA AIE policy and programs.

1. It is suggested that the NEA reconfirm and substantially increase its support of curriculum development and implementation, and program evaluation efforts in each of the arts disciplines. The AIE Program's overall emphasis on and fiscal support of the artist residency program should be substantially decreased.

The NEA needs to reassert itself as a visionary leader in the field of arts education and make a firm recommitment to the support of programs which focus on the development and implementation of basic arts education curriculum K-12. Many state arts agency level administrators appear to be committed to curriculum building and expansion in the arts as well as a more thorough integration of artist residencies into the regular school curriculum. Yet a large portion of AIE funding continues to be awarded for the support of traditional basic skill, process, and technique-oriented residencies. That many teachers and resident artists simply do not have the knowledge or expertise required to design and implement more broadly-conceived, culturallyintegrative ants curricula and residency programs is widely acknowledged. It is highly probable that the laxness of AEPG requirements at the federal level foreshadows an increased laissez-fairism at the state and local levels as well. The facilitation of artist residencies is familiar turf for state and local arts agencies and undoubtedly much easier, more comfortable, and immediately gratifying than the complex and arduous tasks of curriculum development and implementation. The NEA should take precautions that its AIE funding policies do not have the wrong incentives for behavior or lack the incentives necessary to keep state arts agencies on task.

2. Incentives should be built into the AIE Program to encourage limited and deliberate usage of the artist residency and resident artist. 
The inherently elitist nature of the residency program should be recognized and exploited. Artist residencies should be used for one purpose only - to augment an existing and excellent arts curriculum. To receive federal and state support for the implementation of a residency and to be invited to work in-residence should be considered high honors. Artists' salaries should be substantially raised, and taxpayers and residency host expectations should be commensurate.

A limited number of schoolwide performance assemblies and other kinds of short-term demonstration-type residencies might be continued as a legitimate means to introduce new art forms and encourage the establishment of arts programs on a districtwide basis. Such introductory assemblies/ residencies would need to be tailored specifically to effect the ultimate goal of the establishment of comprehensive school arts programs and should be offered to schools at the lowest possible cost. Special presentations/ dlscusslons/workshops for school administrators, teachers, and parents would need to be included as a basic component of every introductory assembly/residency. Attendance for school administrators and host teachers should be mandatory. Eligibility for introductory programs should be restricted to two consecutive years (or two years within a three-year period). Because of the tumover in district and school administration, teaching staff, and of course, graduating and incoming students, procedures might be put into effect so that a school district might regain eligibility for introductory arts services every six to eight years or so. The design and provision of high quality teacher and student guidebooks - a written curriculum if you will should be mandatory support materials for all introductory assembly/ residency programs. School-based and community performing arts touring programs and art exhibitions should be funded through other agency grant programs in direct support of AIE goals.

3. The establishment of curriculum development/teacher in-service consortiums should be strongly encouraged and wellsupported by the NEA.

The NEA should help facilitate the establishment of regional, state, and multi-county curriculum development/pre K-12 teacher in-service consortiums which utilize the front line expertise of the arts specialist and district arts coordinator responsible for the development, Implementation, and administration of outstanding school arts programs. Arts educators of the highest calibre (pre-kindergarten through university) should be identified and duly employed in the design, development, and oversight of the consortiums. After having successfully participated in the curricular augmentation of several of the best arts education programs a state has to offer, artists should be recrulted as consortium guest presenters, instructors, and consultants. Whenever possible, art historians, art critics, and aestheticians should be brought to the institutes to serve as guest lecturers and curriculum consultants as well. All of these individuals would begin to form an everexpanding "elite garde" - essential, accessible, and extremely valuable 
statewide professional arts education resource teams committed to the implementation of basic arts education in every elementary and secondary public school. The consortiums might also offer special courses for highly motivated elementary classroom teachers and secondary social studies and history teachers interested in the integration of the arts into the regular school curriculum. Arts educators and artists could collaborate on the design of courses to be offered as prerequisites for artists seeking inclusion on state arts agency "artist rosters" (a pre-approved listing of suggested artists to serve in-residence) as well.

The facilitation of these kinds of activities should be the main focus of the NEA AIE Program. In this way, the voice of the arts community would be systematically strengthened and incorporated into arts education curricula and practice.

4. The primary focus of all residency activity should be directed specifically toward the schools and occur within the school day.

The Endowment's shift of emphasis away from school partnerships evidenced by the explication of its new number one AIE Program goal -- i.e. that the "substantial arts education experiences" the NEA seeks to provide "need not occur solely in or during the school day" but "may take place in cultural organizations, during after-school programs or school vacation periods, etc." - should be quickly checked. AIE monies are severely limited and should be reserved for the support of initiatives such as curriculum development, teacher in-service, and the development and testing of program and student evaluation methodologies in the arts -- initiatives which are widely acknowledged as potentially effective tools for improving the quality of arts education on a wide ranging socioeconomic and geographic scale. In order for partnerships between arts and cultural organizations and educational institutions to take root and flourish, competition for the same resources must be minimized.

\section{Resident artists should be required to work with students and teachers for the full-school day.}

The requirement that half of the residency day be reserved for artists to pursue their own creative endeavors and so that students may see how a "real" artist plies his or her trade does not seem to work for anyone concerned. Kenneth Marantz's A Parable describes the inefficacy and absurdity of the situation perfectly:

And they took lion from his home and placed him in a 200. And they provided for his needs with space to roam and plenty to eat. But, said his keepers, you must not go beyond these limits nor may you hunt your food. And every day from 9:00 in the morning until 5:00 in the evening and sometimes at night people will come to look at you; and they expect you

Working Papers in Art Education 1992 
to roar and claw the bark from the trees and tear at the hunks of meat we throw to you so they might learn what it is a lion does.

And thus did man, in his infinite wisdom, create a Lion-in-Residence (1978, p. 67).

Artists should not be brought into schools to merely reside; they should be invited into schools to impart knowledge and expertise - as well as to gain it. This requires the entire school day.

6. All AIE programs (federal and state) should be staffed by experienced arts educators; the NEA should take the lead in this practice.

If the Endowment's expanded vision of arts education programming is to be realized, its own AIE Program and those of the state arts agencies will need to be administered by persons with considerable firsthand knowledge and expertise in the development and implementation of comprehensive arts education curricula and policy. That state arts agencies were reported as having protested "that their agencies/staff are not qualified to administer a program of curriculum development, teacher training, and student assessment" (Cleaver, p. 2) should alert arts agency leadership to the needs for hining AIE coordinators and staff members who are qualified to meet such worthy and essential challenges. If state arts agencies continue to be unable to address these issues because of the limitations of their own staff, then perhaps the Endowment would be wise to open up AEPG application to other more qualified and accommodating arts, cultural, and educational institutions and organizations.

7. An NEA agency-wide educational policy should be fully defined and aligned across the various grant programs.

"Educational" funding is available to arts institutions and cultural organizations through several other NEA grant programs in addition to the AIE Program. Grant descriptions indicate little cohesiveness or relation between the kinds of projects that recelve Congressional earmarked funds for education from one program to the next, however. Although promulgated as such in Toward Civilization, the NEA's definition of "basic arts education" is not an accepted agency-wide definition but rather AIE Program-specific only (Smith, 1992). The Endowment should conduct a careful study of the kinds of educational projects supported through its various grant programs and formulate a more cohesive and clearly articulated agency-wide eduction policy. Criteria which support the AJE Program's goal of making the arts basic through the advancement of comprehensive K-12 arts education programs should be instituted within each of the NEA Programs to which educational funding is allocated. 
8. The NEA should rename the AIE Program the "Arts Education Program" to signify its wholehearted entry into the arts education community and total commitment to the widespread implementation of comprehensive school arts programs.

The arts education community needs the input and support of the arts community - not as judgmental outsiders carefully guarding their separate nest egg, separate status, and separate agenda, but as empathic colleagues willing to become involved at even the most mundane levels of development and operation. We are living in a country where a vast portion of the populous does not have access to an education which would enable them to connect the arts to their lives in any meaningful way. That public support for the arts is perennially endangered and frequently denied should not surprise anyone. The symbiotic relationship between the health of the arts and the accessibility of culturally and historically-grounded $\mathrm{K}-12$ arts education programs is clearly apparent. None of us can afford the luxury of educational dilettantism on the part of the government agency which oversees the largest and most visible federally-supported arts education program in the nation.

\section{References}

Biddle, L. (1988). Our government and the arts: A perspective from inside. New York: American Council for the Arts.

Cleaver, C. (1989, June). Memorandum to all AlE coordinators reporting on the June 12-13 NEA AIE overview panel meeting. (AIE Coordinator, Georgia Council for the Arts).

Eisner, E. (1978). "Is the artist in the school program effective?" In R. Smith (Ed.), Artist-in-Schools: Analysis and Criticism. (pp. 4-20).

Urbana, IL: Bureau of Educational Research, University of Illinois at Urbana-Champaign.

Marantz, K. (1978). "A parable." In R. Smith (Ed.), Artist-in-Schools: Analysis and Criticism. (p. 67). Urbana, IL: Bureau of Educational Research, University of Illinois at Urbana-Champaign.

McGeary, C. (1990). Interview. (Chief of the Bureau of Curriculum and Instruction, Pennsylvania Department of Education).

National Art Education Association. (October, 1989). "National Endowment for the Arts Issues Five-Year Planning Document, 1991-1995," in NEAE News. Reston, VA: NAEA, 12-14.

National Endowment for the Arts. (1989a). 1990 AlE application guidelines. Washington, D.C.: NEA

Working Papers in Art Education 1992 
National Endowment for the Arts. (1989b). Arts in education special projects handbook. Washington, D.C.: NEA.

National Endowment for the Arts. (1991) 1990 annuai report. Washington, D.C.: NEA.

South Carolina Arts Commission. (1991.) Arts in Education program guidelines, Columbia, SC.

Smith, J. (1992, June). Telephone interview. (Arts in Education Program Specialist, National Endowment for the Arts). 